\section{Evaluation of Tier 5 Medical Training Initiative opportunities in dentistry}

\author{
M. A. Wilson ${ }^{1}$ and M. Burke ${ }^{2}$
}

IN BRIEF
- Entry to the UK for postgraduate clinical
training is restricted by changes in
immigration procedures.
- Under the Tier 5 MTI selected postgraduate
dentists outside the EEA can obtain short
periods of clinical training in the UK.
Evaluating new training opportunities is
important to ensure that new skills are
acquired, links are made with training
establishments overseas and UK Border
Agency requirements are met.

\begin{abstract}
This paper reviews the first two years of overseas postgraduate dental placements in the UK under the Medical Training Initiative (MTI), which is part of Tier 5 government authorised exchange. Details of the objectives of the programme, the trainees appointed, specialty areas studied and length of training are described. The methods used for assessing the training are reported. It is concluded that the objectives of the MTI have been met in dentistry and that Tier 5 provides a valuable opportunity for establishing international links in postgraduate clinical dentistry.
\end{abstract}

\section{INTRODUCTION}

The points-based system (PBS) of immigration to the United Kingdom was introduced in February 2008. This new system allows the UK Government to control migration for work, study and training. This objective is carried out by the UK Border Agency (UKBA), which enforces customs and immigration law and supports the work of other government departments including the Foreign and Commonwealth Office and the Department of International Development. The UKBA considers applications and issues visas to visit, live work or study in the UK. Underpinning the immigration system, the PBS comprises a five tier framework. Details of the PBS and sponsorship arrangements for migrants can be seen on the UKBA website www.ukba.homeoffice.gov.uk.

Tier 5 was designated to allow people to come to the UK for a limited period of time to satisfy primarily non-economic objectives. Government Authorised Exchange (GAE) is a subcategory of Tier 5, which

\footnotetext{
1*Department of Restorative Dentistry, University Dental Hospital of Manchester, Higher Cambridge Street, Manchester, M15 6FH; ${ }^{2}$ National Advice Centre for Postgraduate Dental Education, The Royal College of Surgeons of England, 35-43 Lincoln's Inn Fields, London, WC2A 3PE

${ }^{*}$ Correspondence to: Dr Margaret A. Wilson Email: mwilson@rcseng.ac.uk
}

\section{Refereed Paper}

Accepted 11 January 2012

10.1038/sj.bdj.2012.175

${ }^{\circledR}$ British Dental Journal 2012; 212: 231-235 includes the Medical Training Initiative (MTI). The MTI also encompasses dentistry.

Traditionally the UK has been an attractive destination for international medical and dental graduates to seek employment and training. Postgraduate training has taken place in UK universities and also National Health Service (NHS) hospitals. The NHS is the largest publicly funded health service in the world and employs highly skilled clinicians within the different specialties of medicine and dentistry. Many clinicians hold dual appointments with a university department and the NHS and are at the forefront of clinical research.

It is therefore important to maintain opportunities for overseas trained doctors and dentists to come to the UK, to learn clinical skills, experience new techniques and be able to return to their own country to put these newly acquired skills into practice. Professional contact with clinicians trained in different countries is also vital for maintaining the UK as a centre of excellence and bringing different perspectives to our healthcare system. The value to the NHS is the maintenance of networks across the world, the exchange of experience and expertise that may enhance patient care and the benefits of highly trained international doctors and dentists working in NHS hospitals. An added bonus is that Tier 5 opportunities can support international development and help foster clinical exchange programmes between the NHS and overseas institutions.
The current immigration regulations for the Tier 5 MTI offer up to a maximum of two years training in the UK. After two years the trainee must leave the UK with no prospect of a UK career via this route or of changing their visa to any other Tier of the PBS. The focus of the MTI is training tailored to individual needs, making use of spare training capacity in the NHS. Service delivery in the NHS was never predicated on MTI posts.

In dentistry, the National Advice Centre for Postgraduate Dental Education (NACPDE) manages Tier 5 placements. The national sponsor for dentistry is the Royal College of Surgeons of England and the sponsorship management system account is held by the NACPDE. ${ }^{1}$ All Tier 5 trainees in dentistry are referred to as International Training Fellows (ITFs) in order not to confuse these posts with existing UK postgraduate training posts.

The start of the scheme was reported in $2010^{2}$ and other successful ITF placements ${ }^{3}$ have also been reported. As it has now been two years since the first ITF arrived in the UK it is time to review and evaluate Tier 5 appointments in dentistry.

\section{METHOD}

The NACPDE set up a system for recording the sponsorship arrangements for Tier 5 in dentistry based on those provided by NHS Professionals - MTI Guide. In addition, a system for monitoring the training experiences of the ITF was introduced at the start of the programme. Evaluation was made by examination of records of posts 
and results of questionnaires and formal reports requested by the NACPDE from 2009-2011. This included details of:

- In-training reports from supervising consultants. Consultants responsible for the training were asked to submit timetables of clinical activity. The timetables were sent to the GDC for approval for the purposes of obtaining a temporary registration order to allow the ITFs to treat patients. In addition the consultants were asked to provide a progress report at the end of each three month period and at the end of the training period (Figs 1a and b)

- Completion of an end of post survey by ITFs including end of post interviews at the NACPDE (Fig. 2)

- Completion of reflective assessment forms after returning home, in order to assess the impact on their experiences in the UK (Fig. 3).

Before arriving in the UK, the ITF sent the NACPDE copies of their CV and training objectives. The supervising consultants sent details of timetables and supervisory arrangements. Each ITF was interviewed at the NACPDE on arrival in the UK and before their departure from the UK. The ITFs were contacted three months after returning home to assess the longer term impact of their training.

\section{RESULTS}

\section{The number of Tier 5 posts}

In the first two years since the introduction of the scheme, 15 overseas dentists have been granted Tier 5 entry visas to enter the UK as International Training Fellows. Of these 15 ITFs, 1 ITF did not enter the UK to take up the post, cancelling at the last minute for personal reasons. The remaining 14 dentists entered the UK for clinical training of varying time periods. In addition to the 15 sponsored posts there were many other enquires and applications which did not achieve sponsorship due to factors such as lack of funding, failure to agree a suitable training post and failure to accept the terms of Tier 5 entry to the UK.

\section{Seniority of ITF posts held and existing postgraduate degrees}

The length of time qualified since being awarded BDS varied between 6 and

\begin{tabular}{|c|c|c|c|c|}
\hline \multicolumn{4}{|c|}{ Tier 5 - Medical Training Initiative } & \multirow{3}{*}{$\begin{array}{l}\text { For internal } \\
\text { use only } \\
\text { ID No.: }\end{array}$} \\
\hline \multicolumn{4}{|c|}{ Name of overseas dentist: } & \\
\hline \multicolumn{4}{|c|}{ Name \&t address of unit: } & \\
\hline Date of review: & $\begin{array}{l}\text { Period covered: } \\
\text { from: }\end{array}$ & & To: & \\
\hline \multicolumn{5}{|c|}{ Please tick the relevant box } \\
\hline & Poor & Satisfactory & Good/Excellent & Notes \\
\hline \multicolumn{5}{|l|}{ Punctuality } \\
\hline \multicolumn{5}{|l|}{ Reliability } \\
\hline \multicolumn{5}{|c|}{ Motivation to learn new skills } \\
\hline \multicolumn{5}{|c|}{ Relationship with colleagues } \\
\hline \multicolumn{5}{|c|}{ Relationship with patients } \\
\hline \multicolumn{5}{|l|}{ Knowledge } \\
\hline \multicolumn{5}{|l|}{ Clinical ability } \\
\hline \multicolumn{5}{|l|}{ Patient after care } \\
\hline \multicolumn{5}{|c|}{$\begin{array}{l}\text { Audit/case presentation } \\
\text { If applicable }\end{array}$} \\
\hline \multicolumn{5}{|c|}{ ANY FURTHER COMMENTS: } \\
\hline \multicolumn{5}{|c|}{ Name of supervisor: } \\
\hline \multicolumn{5}{|c|}{ Signature of supervisor: } \\
\hline Date: & & & & \\
\hline
\end{tabular}

Fig. 1a Three month progress report from consultant

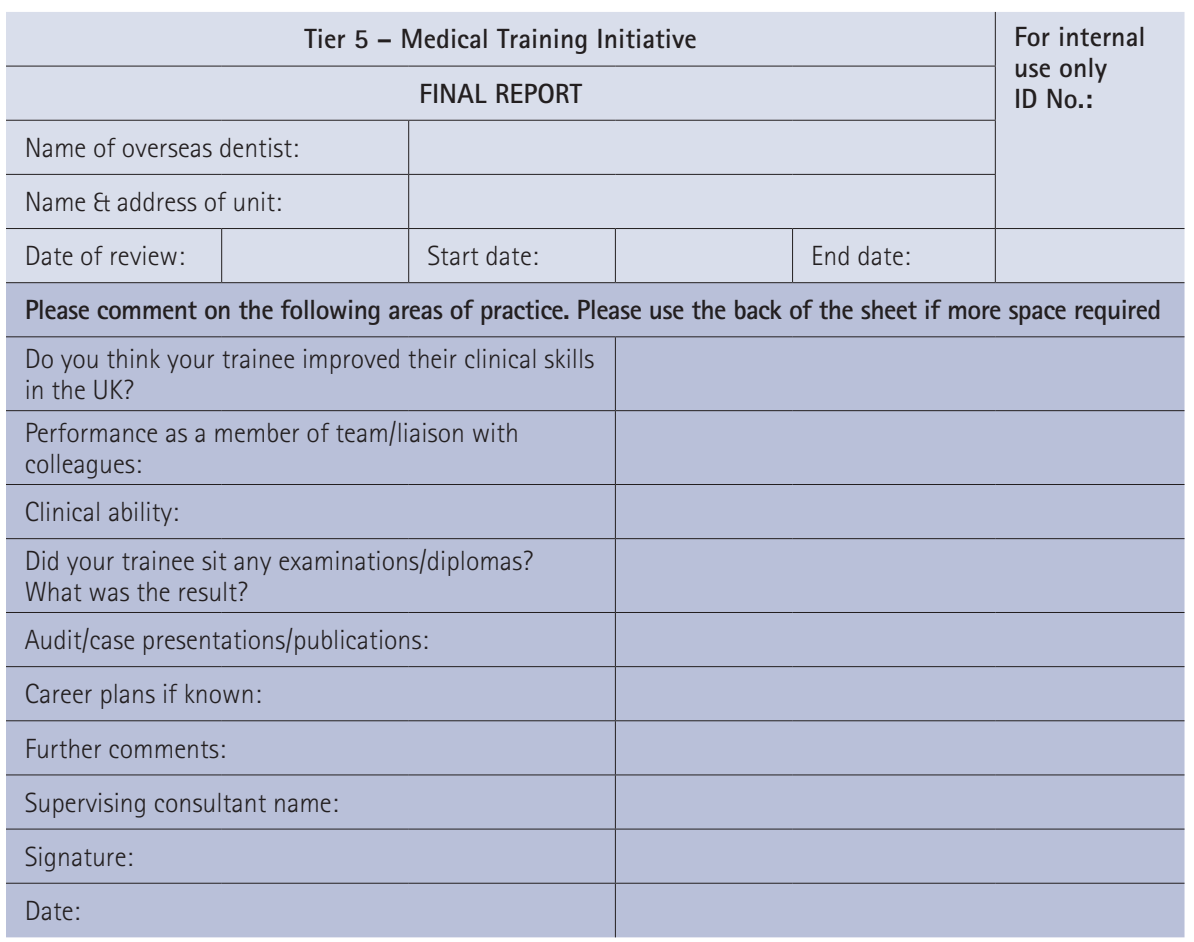

Fig. 1b Final consultant assessment

28 years with a mean of 13.4 years. All the ITFs had higher postgraduate dental degrees including $\mathrm{PhD}$, MDS, MSc, MS, MOrth, MFDS and FRAC.

The ITFs were found to occupy senior positions in their own countries and included the posts of dean, lecturer, senior lecturer, registrar, senior registrar, deputy dean, assistant professor, professor, head of department and reader. Although these titles do not have the exact equivalence to posts with similar names in the UK, the seniority and qualifications of the ITFs were recognised. 


\section{Tier 5 Feedback Form}

\begin{tabular}{|c|c|c|c|}
\hline Would you be happy for us to contact you about 3 months after your return home? & Yes & No & \\
\hline \multicolumn{4}{|l|}{ Visas } \\
\hline $\begin{array}{l}\text { Once you were issued with your certificate of sponsorship number how } \\
\text { easy/difficult did you find obtaining your Tier } 5 \text { visa? }\end{array}$ & Easy & Moderately easy & Difficult \\
\hline \multicolumn{4}{|l|}{ Did you experience any difficulty at the Border Control at the UK airport where you first arrived? } \\
\hline \multicolumn{4}{|l|}{ How long did you stay in the UK? } \\
\hline Did you bring your spouse/partner/children? & Yes & No & \\
\hline \multicolumn{4}{|l|}{ Training } \\
\hline Were you made to feel welcome in your training hospital? & Yes & No & \\
\hline Did your post live up to your expectations? & Yes & No & \\
\hline Was the standard of training you received at the appropriate level for your needs? & Yes & No & \\
\hline Thinking of your training, was it: & Too hard? & Just right? & Too easy? \\
\hline Do you feel you are leaving the UK with new skills? & Yes & No & \\
\hline \multicolumn{4}{|l|}{ If no, please indicate why: } \\
\hline \multicolumn{4}{|l|}{ Overall experience } \\
\hline \multicolumn{4}{|l|}{ What was the best part of your experience? } \\
\hline \multicolumn{4}{|l|}{ What was the worst part of your experience? } \\
\hline \multicolumn{4}{|l|}{ If you could make a change to the whole experience what would it be? } \\
\hline Would you recommend a Tier 5 training experience in the UK to your colleagues at home? & Yes & No & Don't know \\
\hline \multicolumn{4}{|l|}{ If yes, why? } \\
\hline \multicolumn{4}{|l|}{ If no, why? } \\
\hline \multicolumn{4}{|c|}{ On return to your own country - in terms of your own career do you think this period of time in the UK will be beneficial for: } \\
\hline Career development? & Yes & No & \\
\hline Promotion? & Yes & No & \\
\hline Extending your clinical/laboratory skills? & Yes & No & \\
\hline Taking or preparing for examinations? & Yes & No & Don't know \\
\hline Do you think Tier 5 opportunities should be more widely available? & Yes & No & Don't know \\
\hline Did you have any trouble communicating with patients/colleagues in the English language? & Yes & No & \\
\hline \multicolumn{4}{|l|}{ Departure details } \\
\hline \multicolumn{4}{|l|}{ What date are you departing the UK? } \\
\hline \multicolumn{4}{|l|}{ Who is your flight carrier (eg British Airways)? } \\
\hline What is your flight number? & & & \\
\hline If you have any additional comments please make them here: & & & \\
\hline
\end{tabular}

\section{Fig. 2 ITF's assessment of their training in the UK Tier 5 feedback form}

\section{Home countries of ITFs}

The countries of origin of the ITF in dentistry were India, Japan, Malaysia, Qatar, Sri Lanka and Turkey.

\section{Cities of the UK hosting ITFs}

The ITFs were based in acute hospitals and university clinical units in Dundee, Glasgow, Leeds, Liverpool, London, and Manchester. The majority were hosted in London, but several ITFs were based in two centres.

\section{Funding of posts}

Four ITFs had been awarded commonwealth scholarships and all the remaining posts had been funded by the ITF's postgraduate institute, university hospital or employing corporation. None have been self funded, as it is not permissible under MTI regulations.

\section{Specialist areas}

The ITFs had requested training in a variety of specialties. As the ITFs are not restricted to following UK training pathways, there were opportunities of training in areas covering more than one specialty and also the opportunity to learn selected skills from selected parts of a UK training programme. Broadly the specialist areas covered were oral surgery/OMFS $(\mathrm{n}=6)$, orthodontics/ paediatrics $(n=4)$, operative/restorative $(\mathrm{n}=2)$ and oral medicine/pathology $(\mathrm{n}=3)$.

\section{Length of time in the UK}

Two ITFs stayed for two years, the maximum allowed under Tier 5 immigration. 
Five stayed 12 months and 7 stayed 6 months.

\section{Progress reports from consultants}

The General Dental Council (GDC) requires that ITFs are supervised at all times. The consultants submit timetables of clinical activity for consideration by the GDC. At the end of three months and the end of the training period the supervising consultants must submit a report on the progress of the ITF. No adverse reports were received from the supervising consultants.

\section{Assessments by ITFs on completion of training}

All ITFs were asked to assess their experiences on completion of training immediately before returning home. This was completed at the NACPDE, away from their training units (Fig. 2). The comments from the feedback form fell into four main areas: visas and entry to the UK, clinical training, overall experience and benefits of their training experience while in the UK.

\section{Visas/entry to the UK}

Once the certificate of sponsorship was issued by the NACPDE, only one candidate had difficulty in obtaining the Tier 5 visa. This applicant initially did not use the sponsorship certificate, instead entering the UK on a visitor's visa, which meant he was unable to take up the training post. He had to leave the UK and re-enter on a Tier 5 visa. None of the other ITFs had any problems obtaining their visa after securing sponsorship.

\section{Clinical training}

All the ITFs had a positive training experience in the UK. They all reported that they were made to feel welcome in their training hospitals. All except one ITF thought that the posts lived up to expectations. The only negative comment was in a two centre post where in one unit the supervising consultant only permitted observation rather than hands-on experience. All the ITFs reported that they were leaving the UK with new skills.

Comments from ITFs included:

- 'I learned tissue culture methodology and did good research work'

- 'I learned preparation of surgical specimens. My colleagues are now using the pathology report format used in the UK'

\section{Dear}

Re: Three Month Follow up Letter Tier 5

It is now three months since you returned to your post in

I hope that you enjoyed your time in the UK. At the NACPDE we are hoping to follow up dentists who had a period of training in the UK. I would be most grateful if you could spend a few minutes completing the following form and emailing back to the NACPDE.

Thank you

Dr Margaret Wilson

Postgraduate Advisor

1. Since your return following your time in the UK, have you been able to put into practice any of the clinical or research skills you studied in the UK?

\begin{tabular}{l|l}
\hline Yes (go to question 2) & No (go to question 3)
\end{tabular}

2. If yes, do you think these procedures have benefitted patient treatment?

3. If no, why do you think this has been unsuccessful?

4. On reflection, do you consider your experience was beneficial?

Fig. 3 Completion of reflective assessment forms

- 'I am trying to set up a slide exchange programme with different hospitals and have recommended this to our head and neck study group'

- 'It is an essential part of training that we have to experience foreign training to practice as a consultant in our country. The training was excellent'

- 'It was a great experience and I would like to apply again in five years - a gateway to providing skills and professional knowledge'

- 'I expanded my knowledge especially on research into oral cancer epidemiology and also the patient management in oral pre-cancer condition.'

\section{Overall experience}

The unanimous opinion was that the best part of the experience in the UK was the clinical and academic aspect of training. The only adverse comment was about their experience of severe weather in the winter of 2010/11, which coincided with arrival in the UK.

The most commonly reported day-today difficulties were setting up a bank account if in the UK for 6 months but less than 12 months, finding accommodation for a short term let and delays encountered before they could start any clinical work. These delays included waiting for Criminal Record Bureau (CRB) checks and obtaining a temporary registration order from the GDC.

\section{Benefits of their training experience}

In terms of their own career, all ITFs would recommend a Tier 5 experience to their colleagues. A sample of quotes were:
- 'The training brings a very good experience not only at academic level but also social and cultural'

- 'It is a gateway to acquire skills and professional knowledge also an opportunity to meet new friends and colleagues'

- 'A Tier 5 experience should be more widely available.'

All felt that their careers had benefited and their clinical/laboratory skills had been extended. Only one person found moderate difficulty communicating in English and all thought Tier 5 opportunities should be more widely available.

\section{Progress reports from consultants}

Under the regulations of temporary registration, the consultants must supervise the clinical work of the ITF. At the end of each three month period the supervising consultants were required to submit a progress report. No adverse reports have been received about any of the ITFs, either during their training period or in the final assessment.

\section{Reflective assessment by ITFs - 3 months after returning home}

Although all the ITFs agreed to answer some simple questions after reflecting on their experiences in the UK, the response rate has been disappointing with only two ITFs answering. Both of these responses have stated that the benefits of the training have continued.

\section{DISCUSSION}

Appointing an overseas dentist to a MTI post under the Tier 5 visa relies on 
cooperation with consultants, postgraduate deans, hospital trusts, the Faculty of Dental Surgery and the General Dental Council. All the ITFs were granted a temporary registration order by the GDC to cover their period of clinical training in the UK. The requirements for temporary registration can be seen on the GDC website www.gdc-uk.org.

In the majority of cases the initial contact with the NACPDE was from the future trainer. The consultants/professors either had an international reputation for working in a centre of excellence in the UK, extensive clinical research experience or had been to the trainee's country as a lecturer or examiner. The prospective ITF had contacted the trainer about the possibility of training with them in the UK. The NACPDE requires the supervising consultant to complete all the necessary forms ensuring that the dentist is suitably qualified to undertake the requested training, that funding has been secured and a detailed timetable has been produced indicating the supervision of the ITF. Approval of the postgraduate dean is essential to confirm that the training of existing UK trainees will not be compromised.

Although the majority of posts were located in the London Deanery, some were split-centre posts involving two clinical units in different postgraduate deaneries. There were no difficulties in establishing posts split between two different postgraduate deaneries nor different devolved health services. All the ITFs have been superfluous to any UK training or service posts and there have been no complaints about inclusion of ITFs having an adverse effect on existing UK trainees.

All of the dental ITFs who entered the UK under the MTI were experienced clinicians either occupying senior posts or at the end of their specialty training pathway. No newly qualified dentists have been granted visas. To date, all the ITFs have held higher postgraduate degrees awarded by an overseas university. The stated objective of coming to the UK was either to learn a 'niche skill' to enhance their existing training with required overseas training, or for a training experience not available in their country.

As a direct result of their seniority in their home countries they were able to suggest or make changes on their return home. This was one of the original aims of the MTI Tier 5 visa and has been achieved in dentistry. However, senior dentists are not able to be absent from their posts for long periods of time and this is probably why most of the ITFs in dentistry have been in the UK for less than a year. Four dentists were awarded commonwealth scholarships, which are prestigious awards for international study. They are awarded to citizens of commonwealth countries for six months clinical training/research/specialisation. There is intense competition to be selected for one of these awards and the quality of the successful applicant is very high. It is encouraging that these awards are being awarded to dentists in order to come to the UK.

To further evaluate the Tier 5 training opportunities, it was important to record the ITFs' assessment of their training experience in the UK. All the ITFs thought that they had benefited from their experience and intended to make changes to some aspect of their clinical practice, research methods and treatments on return home.

Some problems were reported in relation to setting up a bank account in the UK and finding accommodation. The NACPDE has now included much of this information on its website. As a result of the feedback from the ITFs only staying in the UK for six months, there is a need for clear learning objectives and specific training details to be agreed with their consultant. With shorter visits to the UK, it is also important to have these clear learning objectives and specific training details agreed with their consultant to reduce delays in starting the clinical training. Early contact with the GDC is required so that the ITF has all the required documents to ensure a temporary registration order can be available at the start of the training period. CRB searches are also a requirement, so it is hoped that early contact with departments of human resources will go some way to alleviate any delays.

The UKBA provides an efficient sponsorship system for Tier 5 . The only problems encountered were with the first visa application, when there was difficulty in completing the online applications. A later problem was when flights were cancelled due to volcanic ash. Yet overall the process of applying for a certificate of sponsorship for a Tier 5 visa from the UKBA has proved to be without any problems and no ITF has overstayed their visa in the UK.

The Royal College of Surgeons England is a highly trusted sponsor and the number of Tier 5 visa applications has been agreed with the UKBA for a third successive year. The Faculty of Dental Surgery has played a major role in the sponsorship and awarding of a certificate of completion of training experience signed by the postgraduate dean, training consultant(s), the dean of the FDS and the NACPDE postgraduate advisor.

The relationship between the supervising consultants and the ITFs has been good with several consultants being present when the ITFs were awarded the certificate of completion of training at the FDS. In addition, arrangements have been set in place between some consultants to visit the ITFs overseas, thereby establishing further links with overseas hospitals and universities and satisfying another aim of the Tier 5 initiative. The response to the request for reflective practice has been disappointing. Reflective practice is now a well recognised part of training assessments in the UK but is less well known overseas. As one of the aims of the training is to learn new skills and on return home to put these skills into practice, there is evidence from two of the respondents that this has taken place. Further attempts have been made to contact the non-responders.

\section{CONCLUSION}

Given the results presented in this paper, the initial objectives of the MTI for dentistry under Tier 5 immigration have been satisfied. The scheme has been successful in terms of attracting clinicians of sufficient experience to benefit from their time in the UK. The ITFs have obtained new skills and international networks have been set up. Spare capacity in training has been utilised without detriment to existing trainees in the NHS.

The authors would like to acknowledge the assistance from the Department of Health, the GDC Temporary Registration Team, dean and board members of FDS RCS England and COPDEND for their support with the Tier 5 initiative.

1. Wilson M A. The NACPDE: new opportunities for dentists trained overseas. Ann R Coll Surg Engl (Suppl) 2009; 91: 283.

2. Wilson M A, Butterworth C, Barclay C. A new clinical training scheme for overseas dentists under Tier 5. Br Dent J 2010; 208: 257-258.

3. Wilson M A, Burke M. First tier 5 International training fellow in Dentistry to complete training. Faculty Dent J 2011; 2: 36-37. 